\title{
A Doctoral Program offered by the University of Wales and Penn State Great Valley : An essay in International Collaborations.
}

\author{
David W. Russell \\ The Pennsylvania State University
}

\begin{abstract}
This essay details the establishment and progress of an innovative part-time doctoral program that is available to engineering students at Penn State Great Valley, which is the graduate center for Penn State in the Philadelphia suburbs. The degree is offered under the auspices of the University of Wales at Swansea in the UK. Entrance to the program is highly competitive, based on a dossier that includes postMasters coursework and other scholastic and professional achievements. Once admitted to the program, the student performs three to five years of directed research, culminating in the successful defense of a thesis that is directed by an anonymous external examiner. The paper asserts the synergistic value of a combination of the US and European models for doctoral programs and its intrinsic benefit to international research collaborations.
\end{abstract}

\section{INTRODUCTION and BACKGROUND}

In 1992, two professors, one an ex-patriate of the UK, now resident in the US, and the other anexpatriate of South Africa, now resident in Wales, began a discussion of how their institutions could forma research alliance in the application of artificial intelligence to real-time systems. Both professors were actively engaged in similar research work in this field, however, the major difference in their research programs was the role and demography of participating students.

In Wales, Professor M.G. Rodd heads up a team of MI-time, mainly doctoral, students. These persons typically make application to Swansea and seek to obtain three year contracts of employment funded from either Government or private sector grants and join a research team that is working on a specific project. Most doctoral students secure such research assistantships in the Fall directly after baccalaureate graduation. (A commonly used term for this in the UK is "staying on".) It is fairly uncommon for a Ph.D. candidate to have obtained a Master's degree before embarking on doctoral studies, unless coming from a non-UK institution. The University of Wales at Swansea is part of a multi-campus, but very traditional, British institution and is active in sponsored research.

On the other hand, Professor D. W. Russell, a professor in Electrical Engineering at Penn State Great Valley, has access only to a part-time evening, adult student body seeking professional Master's degrees. The majority of this student body is gainfully employed and already weighted with family responsibilities and obligations, and constitutes what is known in the US, as Generation-X. Penn State Great Valley has offered Master's degrees in Engineering in the Delaware Valley for over thirty years and moved to a new campus located in the midst of a corporate park in 1988. The original graduate center was created to meet the needs 
of engineers employed in the aerospace and computer industry that is located on the "Route 202 high-tech corridor" in the Philadelphia suburbs. The Center currently enrolls almost sixteen hundred graduate students distributed between programs in education, engineering, information science and management programs. Thêse programs are offered under the auspices of the prestigious Colleges of Education, Engineering and Business at Penn State at University Park.

These two researchers decided to investigate the feasibility of a research collaboration, and several visits, that involved faculty and administration,were exchanged between the two locations. Once the validity of such a research collaboration was established, the subject of doctoral candidacy was a natural next step. However, not only were the logistics of the Ph.D. degree in the UK quite different from that in the US, but also the preparation of the community of university undergraduates

\section{UNDERGRADUATE PREPARATION}

Entrance to undergraduate programs in the UK is based on nation-wide, standardized examinations. These are somewhat similar to the familiar SAT but far deeper in content and highly subject specific. By testing students at the end of 10th grade, only those intending to go onto college are allowed to stay in school for 1 lth and 12th. grades, at the end of which, the advanced (and scholarship) level examinations determine if the student is college-material. The student requests to which department within a colleges s/he wishes the results of these Certificates of Education examinations to be sent, and receives an acceptance letter direct from the institution. If no acceptances are forthcoming, a clearing house system then "introduces" students to colleges which may have open places for admission. So, it is quite common for a qualified student to not gain admission to college. (As an aside, for many years, entrance to grammar schools, the only route to college, was based on a national test administered at age 11 years!)

The student is admitted to a particular department or discipline from the onset with little room for change. This is not so in US colleges and universities, where often a student may not declare a major until in the third or fourth year of study. By only offering courses within the major or in supporting subjects (e.g. mathematics) from the freshman year on, the student is exposed to what would be considered advanced studies in the US, while still an undergraduate. The generalized curricula in the US (English, Cultures, Communications, Physical Education) limits the academic progress of the student, while providing life skills and certain aspects of maturity.

Graduation from the UK system is therefore very well suited for continued study at the doctoral level, because of the advanced preparation in mathematics, research and hundreds of hours of instruction within a major field. The US student is better equipped for a profession and in general requires several intermediary steps before being of doctoral calibre. Masters programs and the residency and candidacy requirements of most US universities seek to provide this pedagogy.

\section{RESIDENCY and CANDIDACY}

The major obstacle to doctoral study for fully employed post-Masters students in the US is the residency and candidacy requirements. The residency requirement provides the doctoral student with intensive study leading to candidacy examinations. The rationale varies from college to college, but has its reasoning based in the necessity for departmental academic interests to be understood and also as a preparation for the research project that the student selects. The candidacy examination gatekeeps the quality of preparation and facilitates the construction of a committee that will direct and monitor the project 
through to completion. It is again traditional for the prospective doctoral candidate to be available oncampus during this residency period in a Ml-time mode and it is obvious that research performed by fill-time assistants is more likely to succeed in a timely fashion than for part-time students. This is probably more so in eñgineering and science disciplines than for non-technical programs.

\section{THE SWANSEA - PENN STATE PROGRAM}

The faculty and administrators at Penn State Great Valley and at the College of Engineering at Penn State University Park in collaboration with Professor Rodd in Swansea devised the following "flow chart" that described the process for students to follow, in order to become external, part-time candidates for $\mathrm{PhD}$ at the University of Wales.

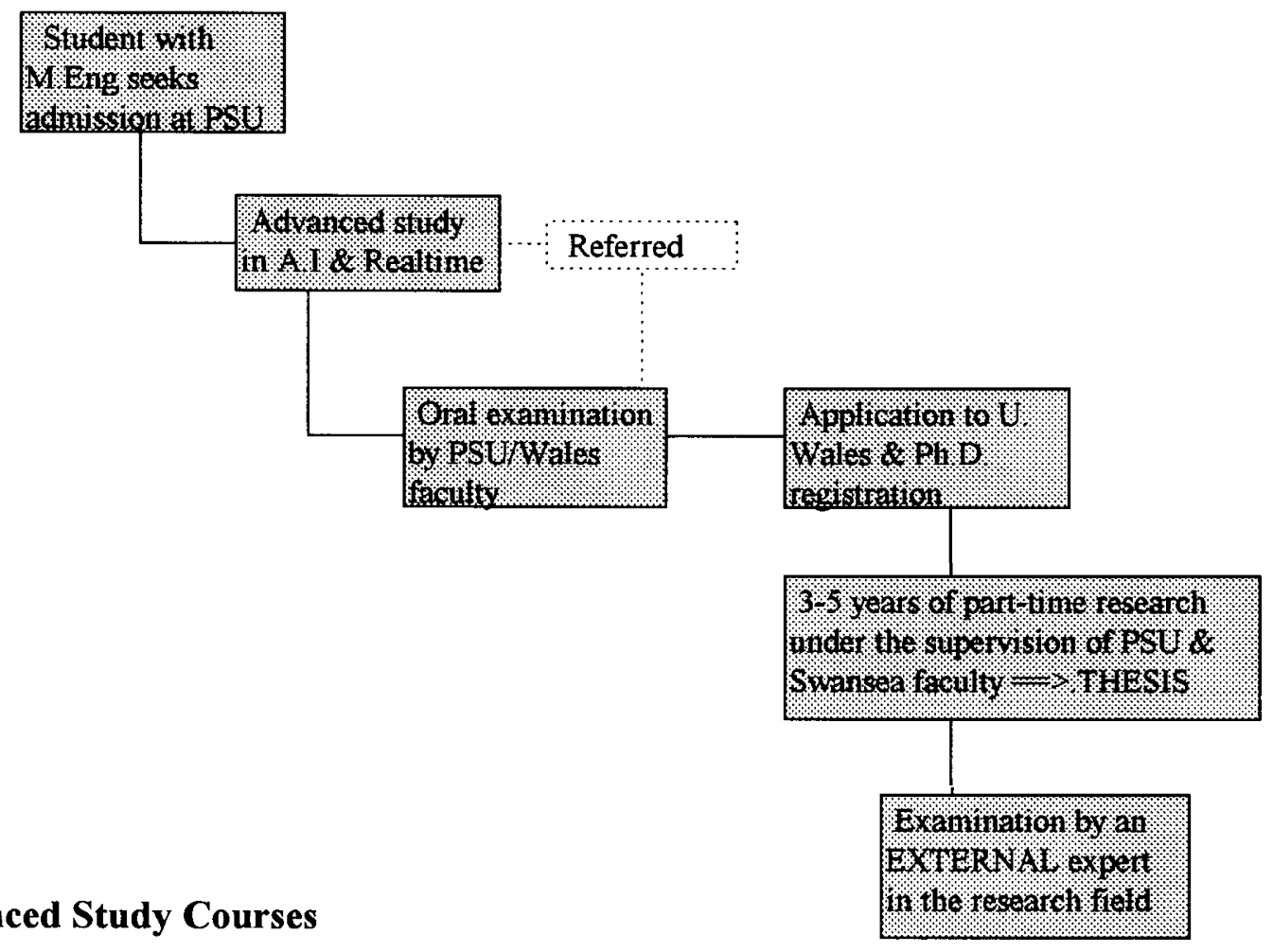

In order to pre-qualify students for the UK degree, a sequence of courses has been designed, so that engineers and computer scientists, with a Master's in Engineering, can begin to adjust to the research environment that their $\mathrm{PhD}$ projects will demand. It is also a consideration that, should a student become able to complete a more traditional $\mathrm{PhD}$ program, these credits maybe transferable to that institution.

\section{Oral Examinations}

Candidates are interviewed at Penn State Great Valley and then by the Electrical Engineering department head at University Park. If deemed a suitable prospect, the student embarks on the 15-credit program of advanced study outlined above. Part of this process involves several research and technical writing courses that are designed to lead the initiate into AI and Real-time research. Once these courses are completed, the student then meets with faculty from Swansea (usually in Wales) and makes several presentations including a proposal for his or her Ph.D. topic. This preliminary visit serves to introduce the US student to the research team in Wales and provides an opportunity for study of past theses in their library, 
set $\mu$ ef email accounts and the presentation of a formal application. The formal supervisors are then assigned to the research plan and the student then sets up an appropriate schedule for fee payment.

\section{Resēarch Projects.}

Prior to this initial visit to Wales, the student is presented with a list of current research interests that is formulated by the research collaboration activity of faculty at PSU and at Wales. In this manner, only projects that most benefit both institutions are presented to the student. The research project is examined for resource availability and any necessary grant activity began in support of the new project. If the project is part of an existing grant the appropriate paperwork is begun. The nature of the agreement between Wales and PSU is mainly that of real-time software, so the resourcing is fairly simple and is threaded into the Penn State Great Valley research budget process.

The project is usually divided into a series of task-lists, each one requiring six months to one year of research investigation and each one building in complexity towards the project goals. The Ph.D. candidate is required to complete these task-lists in order and present their findings to faculty in Wales and to the Penn State steering committee that convenes at University Park under the chairmanship of the Associate Dean of Graduate Studies and Research.

As the task lists are completed, candidates are expected to publish their results in journals and present papers at refereed conferences. The knowledge-base so obtained is directed towards chapters within the final thesis that is prepared during the final year of study (and in fact is the last assigned task. ) The thesis is inspected and reviewed for correctness, comprehensive and scholarship in PSU and in Wales, prior to the external examination.

\section{The EXTERNAL Examination Process}

Once the thesis is deemed defendable, the thesis supervisors begin a search for a suitable expert in the field to act as the external examiner. Once a candidate is located, the senate of the University of Wales must approve the selection and begin the certification process for the award of the Ph.D. degree, should the thesis prove acceptable. The external examiner is sent a copy of the appropriate regulations and the promissory note of a modest fee as payment for service. Approximately three to six months after the external examiner receives the thesis, the formal examination is scheduled (in Wales or Philadelphia based on the geographic proximity of the external examiner.) The examination is chaired by the local department head, and includes the research supervisors from both countries, the candidate and the external examiner. The external examiner then examines in detail the research achievement and the academic propensity of the candidate. Any software that the candidate wrote must be demonstrated; the examiner is allowed to view code segments and question structures and methodologies. The supervisors are present to referee the process against any unfair or irrelevant practice. When the examination is over, the candidate leaves the room and the examiner then proceeds to outline the recommendation that is to be made to the regents of the University of Wales.

\section{CONCLUSION.}

The preceding essay has described the creation, logistics and desirability of a Ph.D. degree in Engineering by part-time study as part of a research collaboration. It is believed that this program is unique to Penn State and a model worthy of emulation. 


\section{EPHQGUE}

That such a pedagogy as described in the essay above is viable and acceptable is left up to the reader. However, it is fair to assert that firstly, much of the time spent in doctoral study in engineering the US is nonresearch oriented, and secondly, the value of qualifying examinations is suspect. If the reader cares to inspect such examinations at any major school in the US, one is always left with feelings of lamentation, such as they really should know this or I can 't believe how standards have dropped etc. If one is willing to step outside of convention for a while and ask oneself Why should the doctor of philosophy degree be limited to "more of the same?", the benefits of a substantial three to four years of creative thinking, evaluation and achievement become very obvious to the professor and attractive to the candidate. It would seem that unrelated (breadth) coursework requirements only delay and dilute the candidate's research achievements and undermines the value of the degree in the global workplace.

\section{DAVID W. RUSSELL}

David W. Russell B. Eng(hons), Ph. D., C. Eng., MBCS., is Faculty Director of Engineering Programs at Penn State Great Valley which is a graduate center of the Pennsylvania State University. Dr. Russell was educated in the U.K and publishes widely in the use of artificial intelligence in real-world systems. 